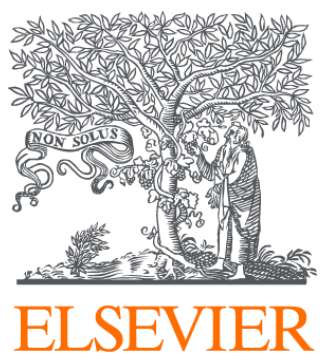

Since January 2020 Elsevier has created a COVID-19 resource centre with free information in English and Mandarin on the novel coronavirus COVID-

19. The COVID-19 resource centre is hosted on Elsevier Connect, the company's public news and information website.

Elsevier hereby grants permission to make all its COVID-19-related research that is available on the COVID-19 resource centre - including this research content - immediately available in PubMed Central and other publicly funded repositories, such as the WHO COVID database with rights for unrestricted research re-use and analyses in any form or by any means with acknowledgement of the original source. These permissions are granted for free by Elsevier for as long as the COVID-19 resource centre remains active. 


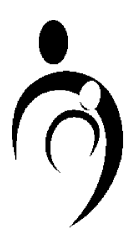

\title{
Management guidelines for obstetric patients and neonates born to mothers with suspected or probable severe acute respiratory syndrome (SARS)
}

\author{
No. 225, April 2009
}

This Clinical Practice Guideline has been prepared by the Maternal Fetal Medicine Committee, reviewed by the Infectious Disease Committee, and approved by the Executive and Council of the Society of Obstetricians and Gynaecologists of Canada.

\section{PRINCIPAL AUTHORS}

Cynthia Maxwell, MD, Toronto ON Alison McGeer, MD, Toronto ON Kin Fan Young Tai, MD, Toronto ON Mathew Sermer, MD, Toronto ON

MATERNAL FETAL MEDICINE COMMITTEE Dan Farine (Chair), MD, Toronto ON Melanie Basso, RN, Vancouver BC Marie-France Delisle, MD, Vancouver BC Lynda Hudon, MD, Montreal QC Savas Menticoglou, MD, Winnipeg MB William Mundle, MD, Windsor ON Annie Ouellet, MD, Sherbrooke QC

INFECTIOUS DISEASE COMMITTEE Mark H. Yudin (Chair), MD, Toronto ON Marc Boucher, MD, Montreal QC Eliana Castillo, MD, Vancouver BC Beatrice Cormier, MD, Montreal QC Andrée Gruslin, MD, Ottawa ON Deborah M. Money, MD, Vancouver BC Kellie Murphy, MD, Toronto ON

\begin{abstract}
A B S T R A C T
Objective: This document summarizes the limited experience of SARS in pregnancy and suggests guidelines for management. Outcomes: Cases reported from Asia suggest that maternal and fetal outcomes are worsened by SARS during pregnancy. Evidence: Medline was searched for relevant articles published in English from 2000 to 2007. Case reports were reviewed and expert opinion sought. Values: Recommendations were made according to the guidelines developed by the Canadian Task Force on Preventive Health Care.
\end{abstract}

Sponsors: The Society of Obstetricians and Gynaecologists of Canada.

\section{Recommendations}

1. All hospitals should have infection control systems in place to ensure that alerts regarding changes in exposure risk factors for SARS or other potentially serious communicable diseases are conveyed promptly to clinical units, including the labour and delivery unit. (III-C)

2. At times of SARS outbreaks, all pregnant patients being assessed or admitted to the hospital should be screened for symptoms of and risk factors for SARS. (III-C)

3. Upon arrival in the labour triage unit, pregnant patients with suspected and probable SARS should be placed in a negative pressure isolation room with at least 6 air exchanges per hour. All labour and delivery units caring for suspected and probable SARS should have available at least one room in which patients can safely labour and deliver while in need of airborne isolation. (III-C)

4. If possible, labour and delivery (including operative delivery or Caesarean section) should be managed in a designated negative pressure isolation room, by designated personnel with specialized infection control preparation and protective gear. (III-C)

5. Either regional or general anaesthesia may be appropriate for delivery of patients with SARS. (III-C)

\footnotetext{
This document reflects emerging clinical and scientific advances on the date issued and is subject to change. The information should not be construed as dictating an

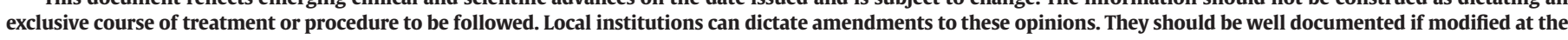
local level.
} 
Caroline Paquet, RM, Trois-Rivières QC Audrey Steenbeek, RN, Halifax NS Nancy Van Eyk, MD, Halifax NS Julie van Schalkwyk, MD, Vancouver BC Tomas Wong, MD, Ottawa ON Disclosure statements have been received from all members of the committees.

J Obstet Gynaecol Can 2009;31(4): 358-364

Keywords

Severe acute respiratory syndrome (SARS)

Pregnancy

Perinatal morbidity

Perinatal mortality

Maternal morbidity

Maternal mortality

Acute respiratory distress

syndrome (ARDS)

Neonatal care
Key to evidence statements and grading of recommendations, using the ranking of the Canadian Task Force on Preventive Health Care.

\begin{tabular}{|c|c|}
\hline Quality of Evidence Assessment* & Classification of Recommendations $\dagger$ \\
\hline $\begin{array}{ll}\text { I: } & \begin{array}{l}\text { Evidence obtained from at least one properly } \\
\text { randomized controlled trial }\end{array}\end{array}$ & $\begin{array}{l}\text { A. There is good evidence to recommend the clinical } \\
\text { preventive action }\end{array}$ \\
\hline $\begin{array}{l}\text { II-1: Evidence from well-designed controlled trials } \\
\text { without randomization }\end{array}$ & $\begin{array}{l}\text { B. There is fair evidence to recommend the clinical } \\
\text { preventive action }\end{array}$ \\
\hline $\begin{array}{l}\text { II-2: Evidence from well-designed cohort (prospective } \\
\text { or retrospective) or case-control studies, preferably } \\
\text { from more than one centre or research group }\end{array}$ & $\begin{array}{l}\text { C. The existing evidence is conflicting and does not } \\
\text { allow to make a recommendation for or against } \\
\text { use of the clinical preventive action; however, }\end{array}$ \\
\hline II-3: Evidence obtained from comparisons between times & other factors may influence decision-making \\
\hline $\begin{array}{l}\text { or places with or without the intervention. Dramatic } \\
\text { results in uncontrolled experiments (such as the }\end{array}$ & $\begin{array}{l}\text { D. There is fair evidence to recommend against the } \\
\text { clinical preventive action }\end{array}$ \\
\hline $\begin{array}{l}\text { results of treatment with penicillin in the 1940s) } \\
\text { could also be included in this category }\end{array}$ & $\begin{array}{l}\text { E. There is good evidence to recommend against the } \\
\text { clinical preventive action }\end{array}$ \\
\hline $\begin{array}{l}\text { III: Opinions of respected authorities, based on clinical } \\
\text { experience, descriptive studies, or reports of expert } \\
\text { committees }\end{array}$ & $\begin{array}{l}\text { L. There is insufficient evidence (in quantity or quality) } \\
\text { to make a recommendation; however, other factors } \\
\text { may influence decision-making }\end{array}$ \\
\hline
\end{tabular}

*The quality of evidence reported in these guidelines has been adapted from The Evaluation of Evidence criteria described in the Canadian Task Force on Preventive Health Care [40].

$\dagger$ †ecommendations included in these guidelines have been adapted from the Classification of Recommendations criteria described in the The Canadian Task Force on Preventive Health Care [40].
6. Neonates of mothers with SARS should be isolated in a designated unit until the infant has been well for 10 days, or until the mother's period of isolation is complete. The mother should not breastfeed during this period. (III-C)

7. A multidisciplinary team, consisting of obstetricians, nurses, pediatricians, infection control specialists, respiratory therapists, and anaesthesiologists, should be identified in each unit and be responsible for the unit organization and implementation of SARS management protocols. (III-C)

8. Staff caring for pregnant SARS patients should not care for other pregnant patients. Staff caring for pregnant SARS patients should be actively monitored for fever and other symptoms of SARS. Such individuals should not work in the presence of any SARS symptoms within 10 days of exposure to a SARS patient. (III-C)

9. All health care personnel, trainees, and support staff should be trained in infection control management and containment to prevent spread of the SARS virus. (III-A)

10. Regional health authorities in conjunction with hospital staff should consider designating specific facilities or health care units, including primary, secondary, or tertiary health care centres, to care for patients with SARS or similar illnesses. (III-A)

\section{Introduction}

Severe acute respiratory syndrome, or SARS, emerged as a highly contagious and life-threatening condition in 2003. By the end of 2003, a total of 8096 cases had been identified internationally, and 774 deaths were reported [1]. Although the majority of cases occurred in South East Asia, 251 probable cases, 187 suspected cases, and 43 deaths were reported in Canada as of September 2003 [2]. It is now known that SARS is caused by a novel coronavirus [3-5] and is easily spread by respiratory droplets and nosocomial contact $[6,7]$. Evidence suggests that health care facilities are the major source for new SARS infections; this was a major factor in the socalled "second wave" of SARS infections in April and May 2003 in the Greater Toronto Area. During this period, affected patients from outlying areas were transferred to a designated tertiary care hospital for treatment in order to limit the number of institutions with active SARS cases. Fortunately, only one case of SARS occurring in pregnancy was reported in Canada [8].

This document summarizes the limited information available regarding SARS in pregnancy and suggests strategies for managing pregnant women and their families in the antenatal, labour and delivery, and postnatal settings. The approach and recommendation of this document may be helpful in creating protocols for other new airborne viral infections.

\section{History of the SARS epidemic}

In February 2003, the first cases of SARS in Canada, presenting as an atypical pneumonia, occurred in the Toronto area. All cases that subsequently occurred in the region can be traced to one of the individuals first affected [6]. Similar outbreaks were reported in Hong Kong [9], Vietnam [10], Singapore [11], Thailand [12], and Taiwan [13]. The diagnosis of SARS was based on viral testing in combination with several clinical findings [1,14].

\section{Treatment and prevention strategies}

Health Canada has outlined the following basic principles for management and treatment of SARS in non-pregnant individuals, as well as recommended testing for SARS [14].

\section{Clinical features, treatment and outcome in non-pregnant SARS patients}

In a study of 144 patients with SARS from the Greater Toronto Area, most patients were exposed in the hospital setting (77\%) [15]. These individuals included health care workers, patients, and visitors to the hospital. The median time from self-reported exposure to onset of symptoms was 6 to 9 days. Almost all patients received empirical antibiotic therapy (95\%) and ribavirin (88\%). Forty percent of patients received steroids.

Of the $20 \%$ of patients admitted to the intensive care unit (ICU), $69 \%$ required mechanical ventilation. There were 8 deaths, or a $6.5 \%$ mortality rate. Predictors of poor outcome (death or admission to the ICU) included increased age, male sex, diabetes, increased neutrophil count, creatine kinase, and urea. In a separate study assessing the outcomes of critically ill patients with SARS in the Toronto area, investigators found that $76 \%$ required mechanical ventilation [16]. Among those requiring ventilation, the mortality rate was $45 \%$. In this study, transmission of SARS within 6 of the intensive care units that were evaluated prompted closure of 73 medical-surgical ICU beds, leading to 164 health care workers being placed in quarantine. 


\section{Effects of SARS in pregnancy}

\section{Pulmonary infections in pregnancy}

The most common non-obstetric infection during pregnancy is pneumonia [17-19], and in a series of studies, it is the third most common cause of indirect obstetric death [20]. In the pre-antibiotic era, maternal mortality was as high as 30\% [21]; more recently, it is reported to be less than $10 \%[18,19]$. Nonetheless, approximately $25 \%$ of pregnant patients with pneumonia will require ventilatory support in a critical care unit [18]. Viral pneumonia is associated with higher morbidity and mortality than bacterial pneumonia responsive to antibiotics [22]. Physiologic changes in pregnancy, including altered cell-mediated immunity [23] and alterations in pulmonary function [24-26], are hypothesized to affect the susceptibility to and severity of pneumonia.

The most detailed reports of viral pneumonia are of cases caused by influenza or varicella.

The influenza epidemic of 1918 had a maternal mortality rate of $30 \%$ to 50\% [27,28]. During the 1957-1958 Asian flu epidemic, the maternal mortality rate was twice that of non-pregnant women, with a higher rate in the third trimester [29]. Ten percent of all deaths related to this influenza epidemic were in pregnant women [27].

The most common fetal complications arising from maternal pneumonia include prematurity resulting from preterm labour (up to $44 \%$ ), intrauterine growth restriction (up to 12\%), intrauterine demise (up to $3 \%$ ), and neonatal demise (up to 12\%) [17-19]. Furthermore, midtrimester exposure to certain viruses (such as varicella) may cause embryopathy and multiple congenital anomalies [30,31].

\section{SARS cases reported in pregnancy}

By May 2003, a total of 10 cases of SARS had been reported in pregnant patients from Hong Kong [32]. Hypoxia, resulting from SARS-related acute respiratory distress syndrome, led to early pregnancy loss in 4 of the 10 cases. To help protect the fetus, pregnant women were given supplemental oxygen to maintain maternal arterial saturation above 95\%, and kept in an upright position. Women receiving mechanical ventilation were maintained in the left lateral position to maximize uterine blood flow. Fetal status was monitored using cardiotocography, and ultrasound examination was used to monitor growth and Doppler flows.

All pregnant patients were treated empirically with broadspectrum antibiotics (e.g., clarithromycin, amoxicillin-clavulanate) to prevent secondary bacterial infections. Ribavirin was reserved for patients with the most severe forms of the illness. As there is no evidence for ribavirin being effective in treating SARS, it is currently not recommended [14]. High dose pulse corticosteroids were administered in several cases [33]. Two deaths occurred in pregnant patients receiving high dose steroids in association with multi-drug resistant Staphylococcus aureus (MRSA) septicemia. The pregnant women thought to be at risk for preterm birth were given additional dexamethasone as prophylaxis for the fetus.

Pregnant patients with SARS were isolated from other antenatal and postnatal patients. A small core group of personnel were assigned to care for these patients exclusively, and all used strict respiratory precautions (such as the use of N95 masks or the equivalent), special gowns, and negative air pressure circulation at all times.

The outcomes in pregnant SARS patients in Hong Kong appeared to be worse than outcomes in their non-pregnant counterparts. Of the seven cases followed at the designated SARS unit, two died (28\%), and four (57\%) were admitted to intensive care for mechanical ventilation. This is in contrast to mortality rates of less than $10 \%$ and mechanical ventilation rates of less than $20 \%$ in non-pregnant, age-matched counterparts. Fortunately, there was no clinical or laboratory evidence of SARS in any of the babies delivered in this series.

No conclusions could be drawn about the safety of planned early delivery by the vaginal route compared with Caesarean delivery, or regional anaesthesia compared with general anaesthesia. However, for the most severe cases, Caesarean delivery and general endotracheal anaesthesia were elected in order to avoid emergency airway issues and to minimize exposure risk for others. As with mothers infected with HIV, SARS-affected patients were advised against breastfeeding in case of possible vertical transmission of the virus.

\section{Antivirals used to treat SARS in pregnancy}

There is no evidence that ribavirin is effective in the treatment of coronaviruses or SARS [15,34,35]. Furthermore, there is evidence of severe toxicity in SARS patients as a result of treatment with ribavirin [36]. In Canada, ribavirin is no longer recommended for treatment of SARS [14].

In vitro evidence suggests a role for the use of human recombinant interferons $\alpha, \beta$, and $\gamma$ in the treatment of SARS [37,38]. Their use in the clinical setting of SARS in pregnancy requires further investigation.

Institutional and personnel issues in the care of pregnant SARS patients

A review of the Hong Kong experience provides important information. For example, all pregnant patients with SARS were managed in one unit at a designated maternity hospital. At one institution with a referral-based obstetrics and gynaecology service, the administration coordinated a transfer arrangement of SARS patients to the designated SARS hospital [39]. All non-urgent ambulatory and elective gynaecological/surgical services were suspended.

The overall number of staff was limited, and only a specific subgroup was assigned to the care of SARS pregnant patients. Communications among medical personnel were by phone or by electronic mail, and teaching conferences were suspended. Clinical teaching was limited to avoid unnecessary exposures. Infection control teaching modules were developed for all obstetrical staff, and all workers were routinely screened for symptoms and signs of infection.

Suggested management guidelines for pregnant women with confirmed SARS

Labour triage and antenatal hospital admission

\section{Actions}

- Assessment is made as to whether the patient has suspected or probable SARS $[1,14]$

- Upon arrival in the labour and delivery triage unit, pregnant patients presenting with fever $>38^{\circ} \mathrm{C}$ and respiratory symptoms and one of the associated symptoms (cough, unexplained hypoxia, shortness of breath, or dyspnea) and history of an exposure to an individual with probable SARS are immediately transferred to the designated isolation room, which is equipped with negative pressure ventilation. This may be a SARS unit in the case of epidemic exposures. If necessary, procedures and delivery may be performed in this isolation room

- A detailed travel and contact history is obtained from the patient

- All staff and visitors should wear the following protective items before entry to the room:

- Gown

- N 95 mask

- Eye protection

- Gloves

\section{Communications}

- Obstetrical staff, infection control and public health authorities are notified immediately 
- Counselling of the pregnant patient should include discussions regarding

- possible fetal effects of SARS viremia

- possible fetal risks of maternal respiratory failure

- obstetrical management at $<24$ weeks' gestation, including option of termination of pregnancy

- obstetrical management at 24-34 weeks' gestation, including discussion of $\beta$-methasone administration, mode of delivery, type of anaesthesia, use of intravenous antibiotics and corticosteroids, possible perimortem Caesarean delivery in the setting of maternal demise

- obstetrical management at > 34 weeks' gestation, including discussion of mode of delivery, type of anaesthesia, use of intravenous antibiotics and corticosteroids, possible perimortem Caesarean delivery in the setting of maternal demise

Delivery

Actions

- Consider administration of stress-dose corticosteroids for mothers treated with steroids antepartum to prevent Addisonian crisis

- To reduce perinatal infection, the newborn should have early clamping of the umbilical cord and early cleansing to remove maternal blood and amniotic fluid

- All neonates born to mothers with SARS should be admitted to the designated negative pressure isolation room in the neonatal nursery

\section{Communications}

- Present anaesthetic options to labouring mother; neither epidural nor spinal anaesthesia is contraindicated and in some cases may be preferable to general anaesthesia. In cases where mothers are already ventilated, general anaesthesia for delivery may be most appropriate

\section{Postnatal management}

Actions

- The mother should not breastfeed until she has recovered from SARS

- To minimize neonatal transmission risk, the mother should be isolated from the neonate until she has recovered from SARS and is considered no longer infectious

\section{Communications}

- Support should be given to the mother and her family to cope with separation from her neonate, potential prolonged maternal hospitalization, parenting issues, neonatal nutrition, and breast engorgement

- As separation of mother and neonate may last for less than 10 days, breast pumping is recommended so that breastfeeding may begin once isolation has been discontinued

\section{Neonatal resuscitation}

\section{Actions}

- Neonates should be admitted to the isolation ward of the neonatal nursery for observation and are considered as potentially infectious until 10 days post-delivery

- Preliminary testing for SARS should be performed, including blood tests and X-rays

- The infant should not be breastfed/given breast milk; formula should be used until the mother is considered no longer infectious.

\section{Communications}

- Parents and family are counselled to look for symptoms and signs of SARS in the mother and newborn, especially in the first 10 days following delivery
Suggested management guidelines for pregnant women with suspected SARS

Labour triage and antenatal hospital admission

Actions

- Initial assessment and management is the same as for pregnant women with probable SARS

- If patient does not have symptoms, then placement in a negative pressure isolation room is not needed

- The patient should be monitored for symptoms and signs of SARS for a 10-day period

Delivery

Actions

- Asymptomatic mothers with a history of SARS exposure should be monitored closely for symptoms and signs (e.g., temperature measured 2-4 times daily), and they should be transferred to the negative pressure isolation room if symptoms or signs develop

- If symptoms or signs develop, delivery, whether vaginal or Caesarean, should occur in the designated SARS delivery room, which is equipped with negative pressure ventilation

Postnatal management

Actions

- Asymptomatic mothers with a history of SARS exposure should be monitored closely for symptoms and signs (e.g., temperature measured 2-4 times daily) and transferred to the negative pressure isolation room if symptoms or signs develop

- The mother should not breastfeed until she has recovered from SARS or is deemed not to have SARS

- To minimize neonatal transmission risk, the mother should be isolated from the neonate until she is no longer potentially infectious

\section{Communications}

- Support should be given to the mother and her family to cope with separation from her neonate, potential prolonged maternal hospitalization, parenting issues, neonatal nutrition, and breast engorgement

- As separation of mother and neonate may last for less than 10 days, breast pumping is recommended so that breastfeeding may begin once isolation has been discontinued

Neonatal resuscitation

Actions

- Neonates born to mothers with potential SARS close contact are considered to be potentially infectious until 10 days postpartum

- Preliminary testing for SARS is performed on the neonate only if mother or neonate has symptoms or signs of SARS

- If the mother remains asymptomatic, consider discharge of the neonate with the mother

\section{Communications}

- Parents and family are counselled to look for symptoms and signs of SARS in the mother and newborn, especially in the first 10 days following delivery, and to report to any findings to the health care team

\section{Summary}

SARS, a life-threatening respiratory illness caused by a novel coronavirus, was responsible for a worldwide outbreak in 2003. SARS has been responsible for serious illness in over 250 Canadians and for 43 deaths since 2003. Given the highly infectious nature of SARS, diagnosis, treatment and containment procedures must be aggressively pursued in all medical communities to prevent epidemic spread. Special consideration must be given to the labour and delivery ward where mothers, their 
babies, and families are potentially placed at risk by exposure to an infected individual. In addition, special procedures must be instituted to protect labour and delivery personnel, who may have prolonged contact with labouring women and substantial exposure to body fluids at the time delivery and neonatal resuscitation. This document outlines a suggested management strategy for pregnant patients with SARS on the labour and delivery ward. This protocol may be of use for other emerging life-threatening infectious diseases.

\section{Recommendations}

The quality of evidence reported in this document has been assessed using the Evaluation of Evidence criteria in the Report of the Canadian Task Force on Preventive Health Care (Table).

1. All hospitals should have infection control systems in place to ensure that alerts regarding changes in exposure risk factors for SARS or other potentially serious communicable diseases are conveyed promptly to clinical units, including the labour and delivery unit. (III-C)

2. At times of SARS outbreaks, all pregnant patients being assessed or admitted to the hospital should be screened for symptoms of and risk factors for SARS. (III-C)

3. Upon arrival in the labour triage unit, pregnant patients with suspected and probable SARS should be placed in a negative pressure isolation room with at least 6 air exchanges per hour. All labour and delivery units caring for suspected and probable SARS should have available at least one room in which patients can safely labour and deliver while in need of airborne isolation. (III-C)

4. If possible, labour and delivery (including operative delivery or Caesarean section) should be managed in a designated negative pressure isolation room, by designated personnel with specialized infection control preparation and protective gear. (III-C)

5. Either regional or general anaesthesia may be appropriate for delivery of patients with SARS. (III-C)

6. Neonates of mothers with SARS should be isolated in a designated unit until the infant has been well for 10 days, or until the mother's period of isolation is complete. The mother should not breastfeed during this period. (III-C)

7. A multidisciplinary team, consisting of obstetricians, nurses, pediatricians, infection control specialists, respiratory therapists, and anaesthesiologists, should be identified in each unit and be responsible for the unit organization and implementation of SARS management protocols. (III-C)

8. Staff caring for pregnant SARS patients should not care for other pregnant patients. Staff caring for pregnant SARS patients should be actively monitored for fever and other symptoms of SARS. Such individuals should not work in the presence of any SARS symptoms within 10 days of exposure to a SARS patient. (III-C)

9. All health care personnel, trainees, and support staff should be trained in infection control management and containment to prevent spread of the SARS virus. (III-A)

10. Regional health authorities in conjunction with hospital staff should consider designating specific facilities or health care units, including primary, secondary, or tertiary health care centres, to care for patients with SARS or similar illnesses. (III-A)

\section{References}

[1] World Health Organization. WHO guidelines for the global surveillance of severe acute respiratory syndrome (SARS). Available at: http://www.who.int/csr/sars/en/ index.html. Accessed May 20, 2004.

[2] Health Canada. Canadian SARS numbers, 3 September 2003. Available at: http:// www.sars.gc.ca. Accessed May 20, 2004.

[3] Ksiazek TJ, Erdman T, Goldsmith CS, Zaki SR, Peret T, Emery S, et al. A novel coronavirus associated with severe acute respiratory syndrome. N Engl J Med 2003;348:1953-66.
[4] Drosten C, Gunther S, Preiser W, van der Werf S, Brodt HR, Becker S, et al. Identification of a novel coronavirus in patients with severe acute respiratory syndrome. $\mathrm{N} \mathrm{Engl} \mathrm{J}$ Med 2003;348:1967-76.

[5] Peiris JS, Lai ST, Poon LL, Guan Y, Yam LY, Lim W, et al. Coronavirus as a possible cause of severe acute respiratory syndrome. Lancet 2003;361:1319-25.

[6] Poutanen SM, Low DE, Henry B, Finkelstein S, Rose D, Green K, et al. Identification of severe acute respiratory syndrome in Canada. N Engl J Med 2003;348:1995-2005.

[7] Seto WH, Tsang D, Yung RW, Ching TY, Ng TK, Ho M, et al. Effectiveness of precautions against droplets and contact in prevention of nosocomial transmission of severe acute respiratory syndrome. Lancet 2003;361:1519-20.

[8] Yudin MH, Steele DM, Sgro MD, Read SE, Kopplin P, Gough KA. Severe acute respiratory syndrome in pregnancy. Obstet Gynecol 2005;105:124-7.

[9] Lee N, Hui D, Wu A, Chan P, Cameron P, Joynt GM, et al. A major outbreak of severe acute respiratory syndrome in Hong Kong. N Engl J Med 2003:1986-94.

[10] Vu HT, Leitmeyer KC, Le DH, Miller MJ, Nguyen QH, Uyeki TM, et al. Clinical description of a completed outbreak of SARS in Vietnam, February-May 2003. Emerg Infect Dis 2004; 10:334-8.

[11] Quah SR, Hin-Peng L. Crisis prevention and management during SARS outbreak, Singapore. Emerg Infect Dis 2004;10:364-8.

[12] From the Centers for Disease Control and Prevention. Update: outbreak of severe acute respiratory syndrome-worldwide, 2003. JAMA 2003;289:1918-20.

[13] Hsieh YH, Chen CW, Hsu SB. SARS outbreak, Taiwan, 2003. Emerg Infect Dis 2004;10: 201-6.

[14] Health Canada. Management of severe acute respiratory sydrome (SARS) in adults: interim guidance for health care providers. Health Canada website; July 2, 2003. Available at: http://www.sars.gc.ca. Accessed May 20, 2004.

[15] Booth CM, Matukas LM, Tomlinson GA, Rachlis AR, Rose DB, Dwosh HA, et al. Clinical features and short-term outcomes of 144 patients with SARS in the Greater Toronto Area. JAMA 2003;289:2801-9.

[16] Fowler BR, Lapinsky SE, Hallett D, Detsky AS, Sibbald WJ, Slutsky AS, et al. Critically ill patients with severe acute respiratory syndrome. JAMA 2003;290:367-73.

[17] Benedetti TJ, Valle R, Ledger WJ. Antepartum pneumonia in pregnancy. Obstet Gynecol 1982;144:413-7.

[18] Madinger NE, Greenspoon JS, Eilrodt AG. Pneumonia during pregnancy: has modern technology improved maternal and fetal outcome? Am J Obstet Gynecol 1989;161:657-62.

[19] Berkowitz K, LaSala A. Risk factors associated with the increasing prevalence of pneumonia during pregnancy. Am J Obstet Gynecol 1990;163:981-5.

[20] Visscher HC, Visscher RD. Indirect obstetric deaths in the state of Michigan 19601968. Am J Obstet Gynecol 1971;109:1187-96.

[21] Finland M, Dublin TD. Pneumococcal pneumonias complicating the pregnancy and puerperium. JAMA 1983;250:1027-32.

[22] Rigby FB, Pastorek JG. Pneumonia during pregnancy. Clin Obstet Gynecol 1996;39: 107-19.

[23] Sargent IL, Redman C. Immunobiologic adaptations of pregnancy. In: Reece EA Hobbins JC, Mahoney MJ, Petrie RH, editors. Medicine of the fetus and mother. Philadelphia: JB Lippincott Company; 1992. p. 317-27.

[24] Nyhan D, Bredin C, Quigley C. Acute respiratory failure in pregnancy due to staphylococcal pneumonia. Ir Med J 1983;76:320-1.

[25] Weinberger S, Weiss S, Cohen W, Weiss J, Johnson TS. Pregnancy and the lung. Am Rev Respir Dis 1980;121:559-81.

[26] Leontic E. Respiratory disease in pregnancy. Med Clin North Am 1977;61:111-28.

[27] McKinney P, Volkert P, Kaufman J. Fatal swine influenza pneumonia during late pregnancy. Arch Intern Med 1990;150:213-5.

[28] Larsen JW. Influenza and pregnancy. Clin Obstet Gynecol 1982;25:599-603.

[29] Eickhoff TC, Sherman IL, Serfling RE. Observations on excess mortality associated with epidemic influenza. JAMA 1961:176:776-82.

[30] Balducci J, Rodis JF, Rosengren S, Vintzileos A, Spivey G, Vosseller C. Pregnancy outcome following first-trimester varicella infection. Obstet Gynecol 1992;79: 5-6.

[31] Pastuszak AL, Levy M, Schick B, Zuber C, Feldkamp J, Gladstone M, et al. Outcome after maternal varicella infection in the first 20 weeks of pregnancy. $N$ Engl J Med 1994;330:901-5.

[32] Wong SF, Chow KM, de Swiet M. Severe acute respiratory syndrome and pregnancy. BJOG 2003;110:641-2

[33] So LKY, Lau AC, Yam LY, Cheung TM, Poon E, Yung RW, et al. Development of a standard treatment protocol for severe acute respiratory syndrome. Lancet 2003;361: 1615-7.

[34] Fujii T, Nakamura T, Iwamoto A. Current concepts in SARS treatment. J Infect Chemother 2004;10:1-7.

[35] Cinatl J, Morgenstern B, Bauer G, Chandra P, Rabenau H, Doerr HW. Glycyrrhizin, an active component of liquorice roots, and replication of SARS-associated coronavirus. Lancet 2003;361:2045-6.

[36] Knowles SR, Phillips EJ, Dresser L, Matukas L. Common adverse events associated with the use of ribavirin for severe acute respiratory syndrome in Canada. Clin Infect Dis 2003;37:1139-42.

[37] Cinatl J, Morgenstern B, Bauer G, Chandra P, Rabenau H, Doerr HW. Treatment of SARS with human interferons. Lancet 2003:362:293-4.

[38] Stroher U, DiCaro A, Li Y, Strong JE, Aoki F, Plummer F, et al. Severe acute respiratory syndrome-related coronavirus is inhibited by interferon-alpha. J Infect Dis 2004;189:1164-7.

[39] Haines CJ. The effect of Severe Acute Respiratory Syndrome on a hospital obstetrics and gynaecology service. BJOG 2003;110:643-5.

[40] Woolf SH, Battista RN, Angerson GM, Logan AG, Eel W, Canadian Task Force on Preventive Health Care. New grades for recommendations from the Canadian Task Force on Preventive Health Care. CMAJ 2003;169(3):207-8. 